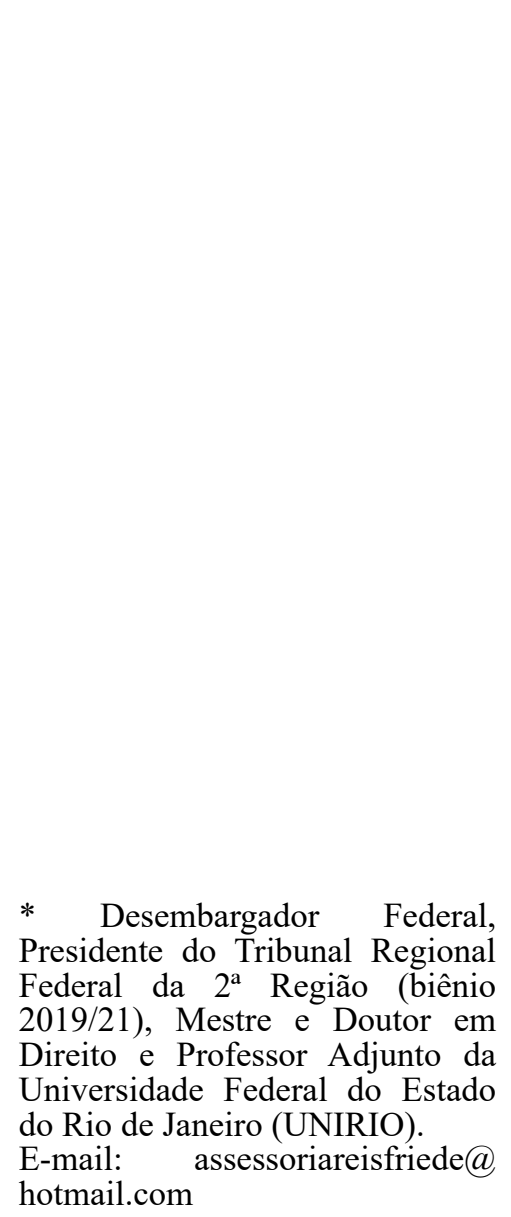

\section{O Ordenamento Jurídico e Seus Atributos Sob a Perspectiva de Norberto Bobbio}

\author{
Judicial System And Its Issues From The Perspective \\ OF Norberto Bobbio
}

Como citar: FRIEDE, Reis. O ordenamento jurídico e seus atributos sob a perspectiva de Norberto Bobbio. Revista do Direito Público, Londrina, v. 14, n. 2, p. 187-201, ago. 2019. DOI: $10.5433 / 24157-108104-1.2019 v 14 n 2 p .188$. ISSN: 1980$511 \mathrm{X}$

Resumo: o presente artigo discorre sobre o ordenamento jurídico e os atributos pertinentes (unidade, coerência e completude) sob a perspectiva de Norberto Bobbio, enfrentando, ainda, o problema das antinomias e respectivos critérios solucionadores.

Palavras-chave: Ordenamento jurídico. Unidade. Coerência. Completude. Antinomia.

Abstract: This paper analyzes the Brazilian judicial system and its characteristics (unity, coherence and completeness) from the perspective of Norberto Bobbio, whilst examining the problem of antinomies and their respective criteria solutions.

Keywords: Judicial system; unity; coherence; completeness; antinomy. 


\section{INTRODUÇÃO}

Em uma definição preliminar, pode-se afirmar que o ordenamento jurídico constituiu-se em um complexo sistema de normas jurídicas (regras e princípios), significação que denota, desde logo, que as normas em questão não se encontram dispostas isoladamente, mas, ao contrário, relacionam-se umas com as outras, formando um genuíno sistema provido de determinados atributos (unidade, coerência e completude), conforme será abordado no presente texto.

\section{ORDENAMENTO JURÍDICO}

O ordenamento jurídico, caracterizado por sua complexidade intrínseca, pode ser traduzido, em linhas gerais, como um conjunto de normas jurídicas. Não obstante a simplicidade de tal definição, trata-se de expressão que abrange muito mais elementos, independente das diversas naturezas e classificações que se lhe possam atribuir, conforme observa Ferraz Junior:

O ordenamento jurídico brasileiro é o conjunto de todas as suas normas, em que estão incluídas todas as espécies que mencionamos [...]. No entanto, não apenas. Nele estão contidos critérios de classificação, como é o caso das classificações legais das coisas (Código Civil Brasileiro de 1916, arts. 43 ss e Código Civil de 2002 , arts. 79 ss) que organizam a matéria, esclarecem as relações de integração, mas não são normas, não constituem imposição vinculante e institucionalizada. Também nele se encontram meras definições (que não se confundem com as definições normativas, isto é, com a imposição compulsória de uma definição) como é, por exemplo, a definição de doação (Código Civil Brasileiro de 1916, art. 1.165; Código Civil de 2002, art. 538): a definição constante do Código é uma orientação, mas que não decide inapelavelmente sobre o sentido, pois a lei pode ter fornecido uma noção que, observando-se o contexto em que se insere (o chamado regime jurídico), pode revelar-se ou como estreito ou demasiadamente abrangente. Descobrir se uma definição é compulsória ou não nem sempre é tarefa fácil, provocando, às vezes, disputas doutrinárias. Há ainda os preâmbulos, exposições oficiais de motivos, em que o legislador esclarece as razões e as intenções pelas quais as normas foram estabelecidas. Nos preâmbulos, aparecem considerações de ordem avaliativa, nomeiam-se valores, indicam-se situações de fato etc. (veja, por exemplo, o Preâmbulo da Constituição de 1988). A própria ordem em que os conceitos aparecem em uma norma é um elemento não normativo, indicando, eventualmente, uma preferência que não precisa ser vinculante. Por exemplo, o art. $4^{\circ}$ da Lei de Introdução ao Código Civil Brasileiro [Lei de Introdução às Normas do Direito Brasileiro] prescreve: 'Quando a lei for omissa, o juiz decidirá o caso de acordo com a analogia, os costumes e os princípios gerais de direito'. A ordem, na enunciação, pode ser uma orientação - primeiro se tenta a analogia, depois, os costumes e, por último, os princípios -, mas ela não é compulsória, não estabelece impositivamente uma relação de superioridade da analogia sobre os costumes e destes sobre os princípios. Um ordenamento, em relação ao qual a pertinência de uma norma a ele é importante para identificá-la como norma válida, além de ser um conjunto de elementos normativos (normas) e não normativos, é 
também uma estrutura, isto é, um conjunto de regras que determinam as relações entre os elementos.(FERRAZ JUNIOR, 2015, p. 139-140).

No preâmbulo do capítulo I da obra intitulada Teoria do Ordenamento Jurídico, Bobbio (1999, p. 19) menciona uma frase cuja essência sintetiza boa parte do conteúdo teórico a ser desenvolvido no presente texto: "as normas jurídicas nunca existem isoladas, mas sempre em um contexto de normas com relações particulares entre si". A presente citação evidencia, em primeiro lugar, que "as regras jurídicas constituem sempre uma totalidade", isto é, formam um ordenamento jurídico, não obstante a existência de normas das mais variadas naturezas temáticas (constitucionais, processuais, penais, civis, administrativas, eleitorais, tributárias, ambientais, etc). Da mesma forma, a referida elocução põe em relevo a importância não apenas do estudo da norma jurídica individualmente considerada (assunto a ser abordado no âmbito da Teoria da Norma), mas, também, de sua inter-relação com outras normas integrantes de um dado sistema, vocábulo que, segundo argumenta Soares (2013, p. 111), pode ser semanticamente definido como "toda ordenação racional de elementos naturais ou sociais, a qual pode ser decomposta analiticamente em duas dimensões", quais sejam, o repertório (elementos que integram o sistema) e a estrutura (padrão de organização dos referidos elementos sistêmicos).

Bobbio, reconhecendo que a norma jurídica era tradicionalmente a única perspectiva através da qual se estudava o Direito, posto que não se concebia o ordenamento jurídico como um objeto autônomo de estudo, propõe, na aludida obra, uma teoria destinada a analisá-lo, separada e particularmente. Assim, diante da verificação de que as normas jurídicas não existem, mas, sim, coexistem, é possível afirmar que a Teoria do Ordenamento Jurídico constitui-se em uma das mais relevantes contribuições de Bobbio para a compreensão do fenômeno jurídico no seu aspecto global. Afinal, conforme afirma o autor italiano, o ordenamento jurídico, "além de regular o comportamento das pessoas, regula também o modo pelo qual se devem produzir as regras". Igualmente considerando o caráter sistêmico inerente ao ordenamento jurídico, Kelsen (1987, p. 207), na célebre Teoria Pura do Direito, assevera que "todas as normas cuja validade pode ser reconduzida a uma e mesma norma fundamental formam um sistema de normas, uma ordem normativa". Nota-se, portanto, que Kelsen e Bobbio, nas mencionadas obras, procuram demonstrar que o fenômeno jurídico não é representado apenas pela norma particularmente concebida, mas também por um autêntico sistema normativo.

A doutrina nacional também alude a tal caráter sistêmico do ordenamento jurídico, atributo assinalado, por exemplo, por Silva (2015, p. 35), mormente quando afirma que o Direito é um "fenômeno histórico-cultural, realidade ordenada, ou ordenação normativa da conduta segundo uma conexão de sentido", consistindo, portanto, em um "sistema normativo", fenômeno que se operou ao longo do tempo, conforme explica Lafer:

A ideia de sistema constitui um aspecto fundamental da contribuição do Direito Natural à jurisprudência europeia, que deixou de limitar-se à exegese e à interpretação prudencial de textos singulares e passou a ter características de 
uma estrutura lógico-demonstrativa. Ora, transposta e positivada pelos códigos e pelas constituições a visão jusnaturalista de um Direito racional e sistemático, foi perdendo significado a ideia de outro Direito que não o Direito do Código e da Constituição. Por isso, o fundamento do Direito deixou de ser buscado nos ditames da razão e passou a afirmar-se como a vontade do legislador, independentemente de qualquer juízo sobre a conformidade desta vontade com a razão. Nesse sentido, o processo de laicização e sistematização do Direito terminou por confluir com o fenômeno da crescente positivação do Direito pelo Estado, que é outro processo característico no mundo moderno. (LAFER, 1988, p. 39)

\section{ATRIBUTOS DO ORDENAMENTO JURÍDICO}

Bobbio, em sua Teoria do Ordenamento Jurídico, discorre sobre os atributos da unidade, coerência e completude do ordenamento jurídico, refletindo a respeito das seguintes questões: a) As normas jurídicas que integram um determinado ordenamento constituem uma unidade? b) $\mathrm{O}$ ordenamento jurídico pode ser entendido como um sistema coerente? c) $\mathrm{E}$, da mesma forma, pode ser considerado completo? As respostas para tais questões serão expostas a seguir.

\subsection{Unidade}

É cediço que as normas jurídicas que integram o ordenamento jurídico não se encontram isoladas, mas interligadas e entrelaçadas, constituindo um todo harmônico. As normas, como as pessoas, não vivem isoladas, mas em conjunto e, como consequência, formam o que se denomina ordenamento jurídico.

De acordo com Kelsen, um dado conjunto de normas jurídicas, para que possa efetivamente formar um ordenamento jurídico, precisa ser dotado, entre outros predicados, de unidade. Assim, segundo tal qualidade, as normas que integram determinado sistema normativo podem ser reconduzidas a uma única norma, aquela que Kelsen denominou de norma fundamental, caracterizando o Direito como uma unidade institucional.

Como a norma fundamental é fundamento de validade de todas as normas pertencentes a uma mesma ordem jurídica, ela constitui a unidade na pluralidade destas normas. Esta unidade também se exprime na circunstância de uma ordem jurídica poder ser descrita em proposições jurídicas que não se contradizem (KELSEN, 1987, p. 220).

O texto acima transcrito permite inferir que Kelsen considera válida uma norma jurídica quando se fundamenta em outra norma que lhe é hierarquicamente superior, ou seja, a norma inferior decorre de uma derivação daquela que lhe é superior, concepção da qual se extrai uma visão hierarquizada e escalonada do sistema, representado por uma pirâmide normativa. Diante de tal pensamento kelseniano, e conforme referido por Soares (2013, p. 113), "uma norma jurídica não vale somente porque tem determinado conteúdo", vale dizer, "porque seu conteúdo pode ser 
deduzido materialmente pela via de um raciocínio lógico de um preceito normativo superior, mas porque ela é criada de uma forma determinada pela normatividade jurídica superior".

Significa afirmar, pois, que a validade de uma norma jurídica deve ser analisada sob os prismas material (o conteúdo da norma inferior deve ser compatível com o que prescreve a norma superior) e formal (a norma inferior deve ser produzida de acordo com a forma prescrita pela norma superior, ou seja, pelo órgão competente para elaborá-la, e em conformidade com o procedimento previsto para tal mister). Por exemplo, assevera o art. $5^{\circ}$, inciso XXXIX, da Constituição de 1988 que "não há crime sem lei anterior que o defina, nem pena sem prévia cominação legal". Posteriormente, prevê o art. 22, inciso I, da Lei Maior que compete privativamente à União legislar sobre Direito Penal, do que se infere que a validade formal de uma lei penal (norma inferior) exige que sua produção obedeça ao disposto no Texto Magno. Assim, somente ao Congresso Nacional (Senado Federal e Câmara dos Deputados) cabe elaborar uma lei de natureza penal, a ser sancionada pelo Presidente da República, em fiel subordinação ao processo legislativo (conjunto de fases pertinentes à elaboração de textos legais) fixado pela norma superior (a Constituição Federal).

Bobbio, para quem a dita norma fundamental configura um "termo unificador das normas que compõem um ordenamento jurídico”, acolhe, nitidamente, a Teoria Escalonada proposta por Kelsen:

Aceitamos aqui a teoria da construção escalonada do ordenamento jurídico, elaborada por Kelsen. Essa teoria serve para dar uma explicação da unidade de um ordenamento jurídico complexo. Seu núcleo é que as normas de um ordenamento jurídico não estão todas num mesmo plano. Há normas superiores e normas inferiores. As inferiores dependem das superiores. Subindo das normas inferiores àquelas que se encontram mais acima, chega-se a uma norma suprema, que não depende de nenhuma outra norma superior, e sobre a qual repousa a unidade do ordenamento. É essa a norma fundamental. Cada ordenamento tem uma norma fundamental. É essa norma fundamental que dá unidade a todas as outras normas, isto é, faz das normas espalhadas e de várias proveniências um conjunto unitário que pode ser chamado 'ordenamento' (BOBBIO, 1999, p. 49).

Observa-se, portanto, que a noção de norma fundamental (Grundnorm), categoria extraída da profícua reflexão de Kelsen, configura, para Bobbio, um dos pontos cardeais, mormente quando o professor italiano afirma que tal norma fundamental cumpre justamente o papel de conferir unidade às demais normas jurídicas integrantes do sistema, funcionando, deste modo, como um autêntico ponto de unidade, sem o qual as normas se constituiriam tão somente em um emaranhado normativo, jamais em um ordenamento. Ademais, consoante explica Bobbio, as "normas de um ordenamento são dispostas em ordem hierárquica", o que resta evidente diante da constatação de que existem normas superiores e inferiores.

Em síntese, de acordo com tal princípio, as normas fundam-se em (ou derivam de) outras normas, constituindo uma linha de descendentes sucessivos a partir de um ascendente comum (a norma fundamental), em relação à qual as demais normas (as normas fundadas) buscam as 
respectivas validades.

\subsection{Coerência}

Uma vez constatado que o ordenamento jurídico configura uma unidade, o ilustre autor italiano passa a conjecturar a respeito de sua sistematicidade, o que significa perquirir se as normas jurídicas que integram um dado sistema são coerentes entre si. Para Bobbio (1999, p. 71) o termo sistema pode ser definido como "uma totalidade ordenada, um conjunto de entes entre os quais existe uma certa ordem". Por conseguinte, o Direito, enquanto autêntico sistema normativo, não condiz com a noção de antinomia, ou seja, não admite a existência de normas (pertencentes ao mesmo ordenamento e tendo o mesmo âmbito de validade) incompatíveis entre si.

Definimos a antinomia como aquela situação na qual são colocadas em existência duas normas, das quais uma obriga e a outra proíbe, ou uma obriga e a outra permite, ou uma proíbe e a outra permite o mesmo comportamento (BOBBIO, 1999, p. 86).

Cabe salientar que o próprio Bobbio $(1999$, p. 87) reconhece que a definição supra não está completa, razão pela qual adverte que o fenômeno da antinomia, para que possa ocorrer no plano fático, requer duas condições, a saber: em primeiro lugar, "as duas normas devem pertencer ao mesmo ordenamento"; e, ainda, ambas as "normas devem ter o mesmo âmbito de validade". A respeito de tal característica e respectiva importância, afirma Bobbio:

A coerência não é condição de validade, mas é sempre condição para a justiça do ordenamento. É evidente que quando duas normas contraditórias são ambas válidas, e pode haver indiferentemente a aplicação de uma ou de outra, conforme o livre-arbítrio daqueles que são chamados a aplicá-las, são violadas duas exigências fundamentais em que se inspiram ou tendem a inspirar-se os ordenamentos jurídicos: a exigência da certeza (que corresponde ao valor da paz ou da ordem), e a exigência da justiça (que corresponde ao valor da igualdade). Onde existem duas normas antinômicas, ambas válidas, e portanto ambas aplicáveis, o ordenamento jurídico não consegue garantir nem a certeza, entendida como possibilidade, por parte do cidadão, de prever com exatidão as consequências jurídicas da própria conduta, nem a justiça, entendida como igual tratamento das pessoas que pertencem à mesma categoria (BOBBIO, 1999, p. 113).

Com efeito, unidade e coerência são reconhecidamente dois atributos que devem necessariamente assinalar um dado Ordenamento Jurídico, conforme já decidiu, inclusive, o Supremo Tribunal Federal.

Os postulados que informam a teoria do Ordenamento Jurídico e que lhe dão o necessário substrato doutrinário assentam-se na premissa fundamental de que o sistema de direito positivo, além de caracterizar uma unidade institucional, constitui um complexo de normas que devem manter entre si um vínculo de essencial coerência. O Ato das Disposições Transitórias, promulgado em 1988 
pelo legislador constituinte, qualifica-se, juridicamente, como um estatuto de índole constitucional. A estrutura normativa que nele se acha consubstanciada ostenta, em consequência, a rigidez peculiar às regras inscritas no texto básico da Lei Fundamental da República. Disso decorre o reconhecimento de que inexistem, entre as normas inscritas no ADCT e os preceitos constantes da Carta Política, quaisquer desníveis ou desigualdades quanto à intensidade de sua eficácia ou à prevalência de sua autoridade. Situam-se, ambos, no mais elevado grau de positividade jurídica, impondo-se, no plano do ordenamento estatal, enquanto categorias normativas subordinantes, à observância compulsória de todos, especialmente dos órgãos que integram o aparelho de Estado (BRASIL, 1994).

\subsection{Completude}

Por completude, segundo a lição de Bobbio, "entende-se a propriedade pela qual um ordenamento jurídico tem uma norma para regular qualquer caso". Diante de tal definição preambular, e considerando que a ausência de uma norma é tradicionalmente denominada de lacuna, reveladora de uma imperfeição do sistema, o termo completude, por conseguinte, traduz exatamente a falta de lacuna.

Em outras palavras, um ordenamento é completo quando o juiz pode encontrar nele uma norma para regular qualquer caso que se lhe apresente, ou melhor, não há caso que não possa ser regulado com uma norma tirada do sistema (BOBBIO, 1999, p. 115).

Bobbio (1999, p. 116) identifica a existência de um nexo entre os atributos da coerência e da completude. Para o autor italiano, a noção de coerência exprime a "exclusão de toda situação a qual pertençam ao sistema ambas as normas que se contradizem”, ao passo que a completude significa a eliminação "de toda situação na qual não pertençam ao sistema nenhuma das duas normas que se contradizem". Deste modo, incoerente é o "sistema no qual existem tanto a norma que proíbe um certo comportamento quanto aquela que o permite", enquanto que incompleto é o "sistema no qual não existem nem a norma que proíbe um certo comportamento nem aquela que o permite".

Ao analisar historicamente o atributo da completude, Bobbio (1999, p. 119-120) comenta que tal dogma, isto é, "o princípio de que o ordenamento jurídico seja completo para fornecer ao juiz, em cada caso, uma solução sem recorrer à equidade", é considerado, por alguns autores, “como um dos aspectos relevantes do Positivismo Jurídico", sendo fruto, provavelmente, da "tradição românica medieval, dos tempos em que o Direito romano vai sendo, aos poucos, considerado como o Direito por excelência, de uma vez por todas enunciado no Corpus Iuris", dotado de "regras que dão ao bom intérprete condições de resolver todos os problemas jurídicos apresentados ou por apresentar". Tal dogma, segundo afirma Bobbio, é objurgado, pela primeira vez, pela designada Escola do Direito Livre.

Se quisermos criticar o fetichismo legislativo dos juristas, precisaremos em 
primeiro lugar abolir a crença de que o Direito estatal é completo. A batalha da Escola do Direito Livre contra as várias escolas da exegese é uma batalha pelas lacunas. Os comentadores do Direito constituído acreditavam que o Direito não tivesse lacunas e que o dever do intérprete fosse somente o de tornar explícito aquilo que já estava implícito na mente do legislador. Os sustentadores da nova escola [a Escola do Direito Livre] afirmam que o Direito constituído está cheio de lacunas e, para preenchê-las, é necessário confiar principalmente no poder criativo do juiz, ou seja, naquele que é chamado a resolver os infinitos casos que as relações sociais suscitam, além e fora de toda a regra pré-constituída (BOBBIO, 1999, p. 123).

Não obstante a crítica acima, os defensores do dogma da completude lançaram mão de uma série de argumentos para combatê-la, sendo o primeiro deles o que Bobbio convencionou chamar de espaço jurídico vazio, assim explicado:

Um caso ou está regulado pelo Direito, e então é um caso jurídico ou juridicamente relevante, ou não está regulado pelo Direito, e então pertence àquela esfera de livre desenvolvimento da atividade humana, que é a esfera do juridicamente irrelevante. Não há lugar para a lacuna do Direito. [...]. Até onde o Direito alcança com as suas normas, evidentemente não há lacunas; onde não alcança, há espaço jurídico vazio e, portanto, não há lacuna no Direito, mas a atividade indiferente ao Direito (BOBBIO, 1999, p. 129).

Em síntese, a teoria em questão apregoa que o ordenamento jurídico não possui lacunas, notadamente "porque, onde falta o ordenamento jurídico, falta o próprio Direito e, portanto, devese falar mais propriamente em limites do ordenamento jurídico do que de lacunas" (BOBBIO, 1999, p. 132). O ponto fraco de tal argumento, diz Bobbio (1999, p. 130), reside no fato de que a teoria do espaço jurídico vazio "nasce da falsa identificação do jurídico com o obrigatório", o que levou o mencionado autor a formular a seguinte indagação: "aquilo que não é obrigatório, e, portanto, representa a esfera do permitido e do lícito, deve ser considerado juridicamente irrelevante ou indiferente? Aqui está o erro".

Tendo em vista o insucesso da teoria anterior (que alude à existência de um espaço jurídico vazio), os adeptos da ideia de completude desenvolveram uma nova proposição, sustentando, da mesma forma, não haver lacunas, "mas pela razão inversa, isto é, pelo fato de que o Direito nunca falta".

Uma norma que regula um comportamento não só limita a regulamentação e, portanto, as consequências jurídicas que desta regulamentação derivam para aquele comportamento, mas ao mesmo tempo exclui daquela regulamentação todos os outros comportamentos. Uma norma que proíbe fumar exclui da proibição, ou seja, permite, todos os outros comportamentos que não sejam fumar. Todos os comportamentos não-compreendidos na norma particular são regulados por uma norma geral exclusiva, isto é, pela regra que exclui (por isso é exclusiva) todos os comportamentos (por isso é geral) que não sejam aqueles previstos pela norma particular (BOBBIO, 1999, p. 133). 
Bobbio (1999, p. 135-136), igualmente, refuta o argumento acima e, para tanto, assevera que no ordenamento jurídico não existem apenas "um conjunto de normas particulares inclusivas e uma norma geral exclusiva que as acompanha", havendo, também, "um terceiro tipo de norma, que é inclusiva como a primeira e geral como a segunda", chamada por Bobbio de norma geral inclusiva, cuja característica é "regular os casos não-compreendidos na norma particular, mas semelhantes a eles, de maneira idêntica"; desta feita, diante de um caso não-regulamentado (havendo, portanto, uma lacuna), utiliza-se a norma geral inclusiva.

\section{O PROBLEMA DAS ANTINOMIAS}

Conforme visto anteriormente, a coerência é uma das características do ordenamento jurídico. Assim, segundo Bobbio (1999, p. 113), “onde existem duas normas antinômicas, ambas válidas, e, portanto, ambas aplicáveis, o ordenamento jurídico não consegue garantir nem a certeza, entendida como possibilidade, por parte do cidadão, de prever com exatidão as consequências jurídicas da própria conduta, nem a justiça, entendida como igual tratamento das pessoas que pertencem à mesma categoria", fenômeno que demanda uma solução a ser buscada no âmbito do próprio sistema normativo, e que originou uma série de critérios destinados a resolver os quadros antinômicos.

\subsection{Classificação das Antinomias}

No âmbito de uma abordagem classificatória, Diniz (2000, p. 470-472) apresenta as antinomias a partir dos seguintes critérios:

a) Quanto à solução: antinomias aparentes ("quando os critérios destinados à solução das antinomias forem normas integrantes do próprio ordenamento jurídico") e antinomias reais (“quando não houver, na ordem jurídica, qualquer critério normativo apto a solucioná-las, razão pela qual a eliminação do problema demanda a edição de uma nova norma”).

b) Quanto ao conteúdo: antinomias próprias ("quando uma conduta aparece, ao mesmo tempo, como prescrita e não-prescrita, proibida e não-proibida, prescrita e proibida") e antinomias impróprias ("que decorrem do próprio conteúdo material das normas"). As antinominas impróprias, por sua vez, desdobram-se em antinomias de princípios ("se houver desarmonia numa ordem jurídica pelo fato de dela fazerem parte diferentes ideias fundamentais"), antinomias valorativas (“quando o legislador não se mostra fiel a uma valoração realizada por ele próprio") e antinomias teleológicas ("quando há incompatibilidade entre os fins alvitrados por uma norma e os meios previstos por outra para a consecução dos aludidos fins").

c) Quanto ao âmbito: antinomias de Direito Interno ("que ocorrem entre normas de um mesmo ramo do Direito ou mesmo entre aquelas de diferentes ramos jurídicos"), antinomias de Direito Internacional ("que aparecem entre convenções internacionais, costumes internacionais, 
princípios gerais de Direito reconhecidos pelas nações civilizadas, decisões judiciárias, opiniões dos publicistas mais qualificados como meio auxiliar de determinação de normas de Direito, conforme preceitua o art. 38 do Estatuto da Corte Internacional de Justiça, normas criadas pelas organizações internacionais e atos jurídicos unilaterais") e antinomias de Direito Interno-Internacional ("que surgem entre uma norma de Direito Interno e uma norma de Direito Internacional, e resumem-se no problema das relações entre dois ordenamentos, da prevalência de um sobre o outro na sua coordenação").

d) Quanto à extensão da contradição: sob tal perspectiva, e segundo categorização proposta por Alf Ross, citado por Diniz (2000, p. 471-472), as antinomias podem ser do tipo: antinomia total-total ("quando uma das normas não puder ser aplicada, em nenhuma circunstância, sem conflitar com a outra"), antinomia total-parcial ("quando uma das normas não puder ser aplicada, em nenhuma hipótese, sem conflitar com a outra, que tem um campo de aplicação conflitante com a anterior apenas em parte") e antinomia parcial-parcial ("quando as duas normas tiverem um campo de aplicação que, em parte, entra em conflito com o da outra e, em parte, não").

\subsection{Critérios Solucionadores das Antinomias}

Kelsen, na sua Teoria Geral das Normas (Allgemeine Theorie der Normen), adverte que o conflito normativo pressupõe a existência de duas normas jurídicas válidas. Destarte, caso uma delas não seja dotada de tal predicado, o fenômeno da antinomia, por consectário lógico, não restará configurado.

Tendo em vista que as antinomias traduzem um nítido conflito aparente de normas, carecem, pois, de critérios que viabilizem a respectiva solução e, em última análise, a manutenção da aludida coerência ínsita ao sistema. Quanto às antinomias e respectivos critérios solucionadores, Bobbio (1999, p. 92-93) também as distingue entre antinomias insolúveis ou reais (quando o ordenamento jurídico não contém regra capaz de resolver o conflito diagnosticado, sendo solucionado, portanto, pela doutrina e jurisprudência a partir de decisões casuisticamente pensadas para cada caso) e antinomias solúveis ou aparentes (quando o ordenamento jurídico contém regra apta a solucionar o conflito aparente de normas, cuja resolução encontra-se nas próprias normas em situação aparentemente conflituosa), sendo estas resolvíveis a partir da incidência de um dos seguintes critérios:

a) O critério cronológico (lex posterior derrogat priori; lei posterior derroga lei anterior): de fácil compreensão, o princípio da lex posterior é adotado, no Brasil, pelo art. $2^{\circ}$, parágrafo $1^{\circ}$, da Lei de Introdução às Normas do Direito Brasileiro (Decreto-Lei $n^{\circ} 4.657 / 42$ ), segundo o qual a lei posterior revoga a anterior quando entre elas houver incompatibilidade.

b) O critério hierárquico (lei lex superiori derrogat inferiori; lei superior derroga lei inferior) preconiza que, havendo duas normas incompatíveis, deve prevalecer a hierarquicamente superior, consequência que se extrai justamente do princípio da hierarquia normativa. 
Uma das consequências da hierarquia normativa é justamente esta: as normas superiores podem revogar as inferiores, mas as inferiores não podem revogar as superiores. A inferioridade de uma norma em relação a outra consiste na menor força de seu poder normativo; essa menor força se manifesta justamente na incapacidade de estabelecer uma regulamentação que esteja em oposição à regulamentação de uma norma hierarquicamente superior (BOBBIO, 1999, p. 93).

c) O critério da especialidade (lex specialis derrogat generali, lei especial derroga lei geral): de acordo com Bobbio (1999, p. 93), "a lei especial deve prevalecer sobre a lei geral”, posto que "representa um momento ineliminável do desenvolvimento de um ordenamento", de modo que "bloquear a lei especial frente à geral significaria paralisar esse desenvolvimento".

Bobbio (1999, p. 97) reconhece que os critérios acima referidos são insuficientes para resolver a denominada antinomia de segundo grau, na qual o problema não consiste mais em uma incompatibilidade entre normas; no caso em particular, incompatíveis são os próprios critérios (cronológico, hierárquico e da especialidade) apontados para a solução da questão antinômica.

Ao lado do conflito entre as normas, que dá lugar ao problema das antinomias, há o conflito dos critérios para a solução das antinomias, que dá lugar a uma antinomia de segundo gra. (BOBBIO, 1999, p. 107).

Resumindo tal insuficiência, Bobbio assevera que o "critério cronológico serve quando duas normas incompatíveis são sucessivas; o critério hierárquico serve quando duas normas incompatíveis estão em nível diverso; o critério de especialidade serve no choque de uma norma geral com uma norma especial". No entanto, conforme adverte o referido autor, "pode ocorrer antinomia entre duas normas contemporâneas; do mesmo nível e ambas gerais” (BOBBIO, 1999, p. 97). De fato, a chamada antinomia de segundo grau revela, na realidade, uma incompatibilidade entre os próprios critérios aplicáveis para a solução do problema. A doutrina, não obstante a existência de controvérsia sobre o assunto, admite, no confronto entre os mencionados critérios (hierárquico versus cronológico, especialidade versus cronológico e hierárquico versus especialidade), as seguintes propostas solucionadoras:

a) Critério hierárquico versus critério cronológico: o primeiro prevalece sobre o segundo, ou seja, incide a norma superior, eliminando-se, por conseguinte, a norma inferior. Assim, "na hipótese de haver conflito entre o critério hierárquico e o cronológico, a meta-regra lex posterior inferiori non derogat priori superiori, resolveria o problema, isto é, o critério cronológico não seria aplicável quando a lei nova for inferior à que lhe veio antes", prevalecendo, pois, "o critério hierárquico, por ser mais forte que o cronológico, visto que a competência se apresenta mais sólida do que a sucessão no tempo" (DINIZ, 2000, p. 475).

b) Critério da especialidade versus critério cronológico: conforme explica Bobbio, tal conflito tem lugar quando uma norma anterior-especial é incompatível com uma norma posteriorgeral. Nesta hipótese, o conflito deve ser resolvido em favor da primeira norma, ou seja, a “lei geral 
sucessiva não tira do caminho a lei especial precedente" (BOBBIO, 1999, p. 108). Deste modo, “em caso de antinomia entre o critério de especialidade e o cronológico, valeria o metacritério lex posterior generalis non derogat priori speciali, segundo o qual a regra de especialidade prevaleceria sobre a cronológica" (DINIZ, 2000, p. 475). No entanto, conforme adverte a autora, "a meta-regra lex posterior generalis non derogat priori speciali não tem valor absoluto, tendo em vista certas circunstâncias presentes. Não há uma regra definida, pois, conforme o caso, haverá supremacia ora de um, ora de outro critério" (DINIZ, 2000, p. 475).

Assim, o Supremo Tribunal Federal, analisando o conflito existente entre uma norma anterior-especial (art. $7^{\circ}$, inciso V, do Estatuto da Advocacia - Lei $n^{\circ}$ 8.906/94) e uma norma posterior-geral (a Lei no 12.258/01, que alterou o art. 295 do Código de Processo Penal - DecretoLei $\mathrm{n}^{\circ} 3.689 / 41$ ), decidiu, para efeito de solução da antinomia, pela incidência do critério da especialidade em detrimento do cronológico.

O Estatuto da Advocacia (Lei $\left.n^{\circ} 8.906 / 94\right)$, em norma não derrogada pela Lei ${ }^{\circ}$ 10.258/2001 (que alterou o art. 295 do CPP), garante, ao Advogado, enquanto não transitar em julgado a sentença penal que o condenou, o direito de "não ser recolhido preso [...], senão em sala de Estado-Maior [...] e, na sua falta, em prisão domiciliar' (art. $7^{\circ}$, inciso V). Trata-se de prerrogativa de índole profissional qualificável como direito público subjetivo do Advogado regularmente inscrito na $\mathrm{OAB}$ - que não pode ser desrespeitada pelo Poder Público e por seus agentes, muito embora cesse com o trânsito em julgado da condenação penal. Doutrina. Jurisprudência. Essa prerrogativa profissional, contudo, não poderá ser invocada pelo Advogado, se cancelada a sua inscrição (Lei n ${ }^{\circ} 8.906 / 94$, art. 11) ou, então, se suspenso, preventivamente, o exercício de sua atividade profissional, por órgão disciplinar competente (Lei ${ }^{\circ} 8.906 / 94$, art. 70, $\S 3^{\circ}$ ). A inexistência, na comarca ou nas Seções e Subseções Judiciárias, de estabelecimento adequado ao recolhimento prisional do Advogado confere-lhe, antes de consumado o trânsito em julgado da sentença penal condenatória, o direito de beneficiar-se do regime de prisão domiciliar (RTJ 169/271-274 - RTJ 184/640), não lhe sendo aplicável, considerado o princípio da especialidade, a Lei $\mathrm{n}^{\circ} 10.258 / 2001$. Existe, entre o art. $7^{\circ}$, inciso V, do Estatuto da Advocacia (norma anterior especial) e a Lei ${ }^{\circ}$ 10.258/2001 (norma posterior geral), que alterou o art. 295 do CPP, situação reveladora de típica antinomia de segundo grau, eminentemente solúvel, porque superável pela aplicação do critério da especialidade ('lex posterior generalis non derogat priori speciali'), cuja incidência, no caso, tem a virtude de preservar a essencial coerência, integridade e unidade sistêmica do ordenamento positivo (RTJ 172/226-227), permitindo, assim, que coexistam, de modo harmonioso, normas em relação de (aparente) conflito (BRASIL, 2012).

No julgado acima, a Corte Suprema deliberou a respeito de um conflito entre os critérios da especialidade (norma anterior-especial, art. $7^{\circ}$, inciso V, do Estatuto da Advocacia) e cronológico (norma posterior-geral, Lei $\mathrm{n}^{0}$ 10.258/01, que promoveu alteração no art. 295 do CPP), fazendo prevalecer o especial sobre o cronológico, ou seja, na hipótese examinada, a Lei $\mathrm{n}^{\mathrm{o}}$ 10.258/01 (norma geral-posterior) não derrogou, ou seja, não revogou parcialmente, o aludido dispositivo do Estatuto da Advocacia (norma anterior-especial). 
Da mesma forma, em outra ocasião, o Pretório Excelso conferiu primazia ao critério da especialidade.

\begin{abstract}
Não se ignora que a existência de antinomia de primeiro grau, quando solúvel, poderá ser superada pela utilização de critérios vários, entre os quais o da especialidade ('lex posterior generalis non derogat priori speciali'), cuja incidência tem a virtude de preservar a essencial coerência, integridade e unidade sistêmicas do ordenamento positivo (RTJ 172/226-227), permitindo, assim, que coexistam, de modo harmonioso, normas em relação de (aparente) conflito. Também não se desconhece que o magistério jurisprudencial dos Tribunais, ao proceder ao exame comparativo entre o art. $1^{\circ}$ da Lei $n^{\circ} 8.137 / 90$ e o art. 334 do $\mathrm{CP}$, reconhece a existência de mencionada antinomia, a ser superada mediante utilização do critério da especialidade [...]” (BRASIL, 2013).
\end{abstract}

No decisum anterior, a Corte Magna, ao verificar um conflito entre os critérios da especialidade (norma anterior-especial, art. 334 do CP, Decreto-Lei $\mathrm{n}^{\circ}$ 2.848/40) e cronológico (norma posterior-geral, art. $1^{\circ}$ da Lei $n^{\circ} 8.137 / 90$ ), corretamente entendeu pela prevalência daquele em relação a este.

c) Critério hierárquico versus critério da especialidade: em tal hipótese, constata-se uma incompatibilidade entre dois critérios fortes (o hierárquico e o da especialidade), isto é, uma norma superior-geral apresenta-se incompatível em relação a uma norma inferior-especial. Na presente hipótese, explica Bobbio que:

A gravidade do conflito deriva do fato de que estão em jogo dois valores fundamentais de todo ordenamento jurídico, o do respeito da ordem, que exige o respeito da hierarquia e, portanto, do critério da superioridade, e o da justiça, que exige a adaptação gradual do Direito às necessidades sociais e, portanto, respeito do critério da especialidade. (BOBBIO, 1999, p. 107)

Segundo leciona Diniz (2000, p. 475), “no conflito entre o critério hierárquico e o de especialidade, havendo uma norma superior-geral e outra inferior-especial, não será possível estabelecer uma meta-regra geral dando prevalência ao critério hierárquico, ou vice-versa, sem contrariar a adaptabilidade do Direito. Poder-se-á, então, preferir qualquer um dos critérios, não existindo, portanto, qualquer predominância".

\title{
CONCLUSÃO
}

Em sua obra Teoria do Ordenamento Jurídico, Bobbio (1999, p. 19) menciona uma frase cuja essência sintetiza boa parte do conteúdo desenvolvido no presente texto: "as normas jurídicas nunca existem isoladas, mas sempre em um contexto de normas com relações particulares entre si”. A presente citação evidencia, em primeiro lugar, que "as regras jurídicas constituem sempre uma totalidade", isto é, formam um ordenamento jurídico. Da mesma forma, a referida elocução põe em relevo a importância não apenas do estudo da norma jurídica individualmente considerada, 
mas, também, de sua inter-relação com outras normas integrantes de um dado sistema.

Bobbio, reconhecendo que a norma jurídica era tradicionalmente a única perspectiva através da qual se estudava o Direito, posto que não se concebia o ordenamento jurídico como um objeto autônomo de estudo, propõe, na aludida obra, uma teoria destinada a analisá-lo, separada e particularmente. Assim, diante da verificação de que as normas jurídicas não existem, mas, sim, coexistem, é possível afirmar que a Teoria do Ordenamento Jurídico se constitui em uma das mais relevantes contribuições de Bobbio para a compreensão do fenômeno jurídico no seu aspecto global.

\section{REFERÊNCIAS}

BOBBIO, Norberto. Teoria do ordenamento jurídico. 10. ed. Brasília: Editora Universidade de Brasília, 1999.

\section{BRASIL. Supremo Tribunal Federal (1. Turma). Recurso Extraordinário no 160.486/SP.} Precatório - Pagamento parcelado - ADCT, art.33 - Natureza Jurídica das normas integrantes do ADCT - Relações entre o ADCT e as disposições permanentes da Constutuição - antonomia aparente - a questção da coerência do ordenamento positivo - recursos extraordinário conhecido e provido. Recorrente: Município de Santos. Recorrido: Santos e Ferreira LTDA. Relator: Min. Celso de Mello, 11 de Outubro de 1994.

BRASIL. Supremo Tribunal Federal (2. Turma). Habeas Corpus HC 109.213/SP. Advogado - condenação penal meramente recorrível - prisão cautelar - recolhimento a "sala de estadomaior" até o trânsito em julgado da sentença condenatória - prerrogativa profissional assegurada pela lei $\mathrm{n}^{\mathrm{o}} 8.906 / 94$ (estatuto da advocacia, art. $7^{\circ}, \mathrm{V}$ ) - inexistência, no local do recolhimento prisional, de dependência que se qualifique como "sala de estado-maior" - hipótese em que se assegura, ao advogado, o recolhimento "em prisão domiciliar" (estatuto da advocacia, art. $7^{\circ}, \mathrm{V}$, "in fine") - superveniência da lei $\mathrm{n}^{\mathrm{o}}$ 10.258/2001 - inaplicabilidade desse diploma legislativo aos advogados - existência, no caso, de antinomia solúvel - superação da situação de conflito mediante utilização do critério da especialidade - prevalência do estatuto da advocacia confirmação da medida liminar anteriormente deferida - pedido de "habeas corpus" deferido. Paciente: Paulo Rogerio Pollak. Advogado: Guilherme Gibertoni Anselmo. Relator: Min. Celso de Mello, 28 de Agosto de 2012.

BRASIL. Supremo Tribunal Federal (2. Turma). Habeas Corpus HC105.181/SC. "Habeas Corpus" - condenação penal pela prática dos delitos de descaminho (cp, art. 334, § 1", "c") e de sonegação fiscal (lei $\mathrm{n}^{\circ} 8.137 / 90$, art. $1^{\circ}$, IV) - suposta ocorrência de antinomia de primeiro grau - alegada inobservância do critério da especialidade, consideradas as regras legais que definem ambas as infrações - incoincidência entre as mercadorias objeto do crime de descaminho e aquelas que figuram nas notas fiscais falsamente elaboradas - sonegação de tributos ocorrida anteriormente à introdução clandestina, no território nacional, dos objetos expostos à venda - denúncia e sentença penal condenatória que demostram a total independência, no caso, das condutas perpetradas - inexistência, na espécie, de situação de conflito a ser superada mediante utilização do critério da especialidade - ocorrência de iliquidez quanto aos fatos subjacentes à impetração - controvérsia que, ademais, implica exame aprofundado de fatos e confronto analítico de matéria essencialmente probatória - inviabilidade na via sumaríssima do "habeas 
corpus" - pedido indeferido. Paciente: Márcio Cardoso. Impretante: Rafael Fonseca Pimentel e Outro. Relator: Min. Celso de Mello, 9de Abril de 2013.

DINIZ, Maria Helena. Compêndio de introdução à ciência do direito. 12. ed. São Paulo: Saraiva, 2000.

FERRAZ JUNIOR, Tercio Sampaio. Introdução ao estudo do direito, técnica, decisão, dominação. 8. ed. São Paulo: Atlas, 2015.

KELSEN, Hans. Teoria pura do direito. 2. ed. São Paulo: Martins Fontes, 1987.

LAFER, Celso. A reconstrução dos direitos humanos: um diálogo com o pensamento de Hannah Arendt. São Paulo: Companhia das letras, 1988.

SOARES, Ricardo M. F. Elementos de teoria geral do direito. São Paulo: Saraiva, 2013.

SILVA, José Afonso da. Curso de direito constitucional positivo. 38. ed. São Paulo: Malheiros, 2015.

Como citar: FRIEDE, Reis. O ordenamento jurídico e seus atributos sob a perspectiva de Norberto Bobbio. Revista do Direito Público, Londrina, v. 14, n. 2, p. 187-201, ago. 2019. DOI: 10.5433/24157-108104-1.2019v14n2p. 187. ISSN: 1980-511X

Recebido em: 10/10/2017.

Aprovado em: 28/01/2019. 